\title{
Effect of different levels and sources of zinc supplementation on quantitative and qualitative semen attributes and serum testosterone level in crossbred cattle (Bos indicus $\times$ Bos taurus) bulls
}

\author{
Nishant KUMAR ${ }^{\mathrm{a}}$, Ramesh Prashad VERMA ${ }^{\mathrm{a}}$, Lallan Prasad SINGH ${ }^{\mathrm{a}}$, \\ Vijay Prakash VARSHNEY ${ }^{\mathrm{b}}$, Ram Sharan DASS ${ }^{\mathrm{c} *}$ \\ ${ }^{a}$ Animal Reproduction Division, Indian Veterinary Research Institute, Izatnagar, 243 122, India \\ ${ }^{b}$ Division of Veterinary Physiology and Climatology, Izatnagar, 243 122, India \\ ${ }^{\mathrm{c}}$ Division of Animal nutrition, Izatnagar, 243 122, India
}

(Received 30 August 2005; accepted 7 July 2006)

\begin{abstract}
An experiment was conducted on 16 crossbred bulls (about 2 years of age, $316.2 \pm$ $0.77 \mathrm{~kg}$ average body weight), divided into groups I, II, III and IV to study the effect of different levels of $\mathrm{Zn}$ supplementation from inorganic and organic sources on semen quality. The animals in the first 3 groups were supplemented with 0,35 and $70 \mathrm{ppm} \mathrm{Zn}$ from $\mathrm{Zn}$ sulfate, respectively and the animals in-group IV were supplemented with $35 \mathrm{ppm} \mathrm{Zn}$ as $\mathrm{Zn}$ propionate. Semen collection and evaluation was done in the first month (to assess semen quality at the start of the experiment) and 7th, 8th and 9th month of experimental feeding to evaluate the effect of supplemental $\mathrm{Zn}$ on semen attributes. We gave 6 months for $\mathrm{Zn}$ feeding, so that 3 sperm cycles of spermatogenesis had passed and the collected semen reflected the complete effect of $\mathrm{Zn}$ supplementation. Six ejaculates from each bull were collected and evaluated for semen quantitative (ejaculate volume, sperm concentration and sperm number per ejaculate) and qualitative characteristics (semen $\mathrm{pH}$, mass motility, individual motility, sperm livability percent and abnormal sperm percent, percent intact acrosome, bovine cervical mucus penetration test, hypo-osmotic sperm swelling test) and activity of seminal plasma enzymes i.e., alkaline phosphatase, acid phosphatase, GOT and GPT. Testosterone level in the blood serum of crossbred bulls was also estimated. Mean values of semen quantitative and qualitative characteristics at the start of the experiment were statistically non significant $(P>0.05)$ in all the crossbred cattle bulls, however, there were statistically significant differences among the bulls of different groups after 6 months of zinc supplementation. Mean ejaculate volume (mL) was $2.37,4.70,5.86$ and 6.38 , respectively in groups I to IV, indicating a statistically significant $(P<0.05)$ higher semen volume in $\mathrm{Zn}$-supplemented groups as compared to the control group of bulls. Similarly, sperm concentration (million. $\mathrm{mL}^{-1}$ ), live sperm $(\%)$ and motility $(\%)$ were significantly $(P<0.01)$ higher in $\mathrm{Zn}$-supplemented groups as compared to the control group. The results of BCMPT and HOSST revealed a significant improvement in sperm functional ability in all the groups supplemented with $\mathrm{Zn}$ as compared to the control group. The activity of alkaline and acid phosphatase in seminal plasma was significantly $(P<0.05)$ higher in the $\mathrm{Zn}$-supplemented groups, whereas GOT and GPT activities in seminal plasma were significantly $(P<0.05)$ lower in the Zn propionate supplemented group as compared to the control group. Testosterone concentration (ng. $\mathrm{mL}^{-1}$ ) in blood serum was significantly higher in animals of groups III and IV, as compared to control group. It may be concluded that $\mathrm{Zn}$ supplementation either in the inorganic or organic form in the diet of crossbred bulls improved the qualitative and quantitative attributes of semen;
\end{abstract}

\footnotetext{
*Corresponding author: rsd@ivri.up.nic.in
} 
however, the number of sperm per ejaculate, mass motility and semen fertility test like bovine cervical mucus penetration was significantly higher in bulls given $\mathrm{Zn}$ in an organic form ( $\mathrm{Zn}$ propionate) as compared to an inorganic form ( $\mathrm{Zn}$ sulfate).

zinc / crossbred bulls / semen / sperm / testosterone / seminal plasma enzyme

\section{INTRODUCTION}

Zinc is an essential trace element required for the action of more than 200 metallo enzymes and plays an important role in polymeric organization of macromolecules like DNA and RNA, protein synthesis and cell division [1]. Zinc plays an important role in prostate, epididymal and testicular functions [2]. Zinc has been reported to influence the process of spermatogenesis [3], controls sperm motility [4], stabilizes sperm membrane [5], preserves the ability of sperm nuclear chromatin to undergo decondensation and modulates sperm functions [6]. Hypozinkemia leads to gonad dysfunction, decreased testicular weight, atrophy of seminiferous tubules and complete cessation of spermatogenesis [7]. Zinc is found in high concentration in the male reproductive tract as well as in semen [8]. The mean concentration of $\mathrm{Zn}$ in the semen of bulls, rams, stallions and boar has been reported as $83.15 \pm 61.61$, $60.46 \pm 35.37,86.20 \pm 45.88$ and $171.74 \pm$ $65.72 \mathrm{mg} \cdot \mathrm{kg}^{-1}$ wet weight of tissue, respectively [9]. The recommended level of zinc in the diet of cattle is $35-40 \mathrm{ppm}$ and is sufficient for normal body functions, but for enhanced immunity, higher levels of zinc have been found beneficial [10]. Similarly, supplementation of zinc as organic/chelated minerals has been found more beneficial as compared to inorganic sources [11-13]. Till date, very little work has been done in crossbred cattle bulls in relation with zinc supplementation. Moreover, the effect of organic zinc supplementation on semen quality has so far not been studied. Most of the studies on zinc supplementation and its effect on semen quality have been conducted in men $[8,14,15]$ and very little information is available regarding zinc supplementation and sperm function test in cattle.

Therefore, the present experiment was conducted to study the effect of higher levels of $\mathrm{Zn}$ supplementation from zinc sulfate and zinc propionate on the quantitative and qualitative characteristics of semen along with testosterone level in the blood serum of crossbred cattle bulls.

\section{MATERIALS AND METHODS}

\subsection{Animals, their feeding and management}

This study was conducted on sixteen young and healthy crossbred cattle (Bos indicus $\times$ Bos taurus) bulls of about 2 years of age, having $316 \pm 0.77 \mathrm{~kg}$ mean body weight, divided randomly into groups I, II, III and IV, comprised of four animals in each group. All the bulls were maintained in the Animal Nutrition Division of Indian Veterinary Research Institute, Izatnagar, and fed on wheat straw and concentrate mixture in the ratio of $1: 1$ to meet their dry matter and crude protein requirement [10]. The basal diet (wheat straw and concentrate mixture) had $32.54 \mathrm{ppm}$ zinc. Concentrate mixture was comprised of crushed maize grain (30\%), soybean meal $(25 \%)$, wheat bran $(42 \%)$, mineral mixture $(2 \%)$ and common salt $(1 \%)$. In addition, the animals were given 0,35 and $70 \mathrm{ppm}$ zinc as zinc sulfate in the first 3 groups, respectively, whereas, $35 \mathrm{ppm}$ zinc as zinc propionate was given to bulls in group IV. All the bulls were kept in a well ventilated shed having a cemented 
floor and arrangements for individual feeding. Clean and fresh drinking water was provided twice daily i.e. at $10.00 \mathrm{am}$ and $3.00 \mathrm{pm}$ to all the animals. Body weights of all the animals were recorded at an interval of 15 days for the formulation of diet and calculation of zinc to be supplemented in the diet of each animal. This feeding practice lasted for 9 months.

\subsection{Collection of semen and evaluation of its quantitative and qualitative characteristics}

The semen from all the groups of bulls was collected in an artificial vagina over a dummy or male partner in the first one month to assess semen characteristics of all bulls at the start of the experiment. In the last 3 months of experimental feeding, 6 ejaculates from each animal were collected to study the effect of $\mathrm{Zn}$ supplementation on semen characteristics. We waited for 6 months to assess the effect of zinc supplementation on semen attributes since the time required to complete one cycle of spermatogenesis (for complete sperm formation and maturation) is 60 days in bulls, so around 3 sperm cycles were passed with zinc supplementation in the diet. This was done in order to ensure that the collected semen reflected complete effect of $\mathrm{Zn}$ supplementation. All semen samples were evaluated for quantitative and qualitative characteristics along with separation of seminal plasma, by centrifuging the semen at $3000 \mathrm{rpm}$ for $20 \mathrm{~min}$, for estimation of seminal plasma enzyme activity.

\subsubsection{Evaluation of quantitative characteristics of semen}

Quantitative characteristics of semen included ejaculate volume, sperm concentration, and sperm number per ejaculate. Ejaculate volume $(\mathrm{mL})$ of semen was recorded to the nearest $0.1 \mathrm{~mL}$ in a graduated glass tube. The concentration of sperm (million. $\mathrm{mL}^{-1}$ ) in the fresh semen was determined using a haemocytometer [16]. The number of sperm present in 80 small squares was counted and the total number was multiplied by 10 millions to get the sperm concentration per $\mathrm{mL}$ of semen. Sperm number per ejaculate was calculated simply by multiplying the concentration of sperm by total volume of semen.

\subsubsection{Evaluation of qualitative characteristics of semen}

It included the assessment of semen $\mathrm{pH}$, mass motility, individual motility, sperm livability percentage and abnormal sperm percentage, intact acrosome percentage, two sperm function tests viz., bovine cervical mucus penetration test (BCMPT) and the hypo-osmotic sperm swelling test (HOSST), and estimation of seminal plasma enzyme activity i.e. alkaline phosphatase, acid phosphatase, glutamic oxaloacetic transaminase [GOT] and glutamic pyruvic transminase [GPT]. Semen $\mathrm{pH}$ was noted immediately after collecting the semen using a digital $\mathrm{pH}$ meter (Century, India). Mass motility of semen was graded from a $0-5$ scale, based on the appearance of waves and swirls created by sperm movement when visualized by keeping one drop of semen on a glass slide, without cover slip, under low power microscopic magnification $(10 \times)$ [16]. Extremely rapid waves or swirl motion of sperms were given a 5 numerical scale, comparatively slower waves and swirls were given a 4 numerical scale and likewise slow moving, extremely slow moving, no movement and non-motile sperm were given 3,2, 1 and 0 numerical scales respectively. The individual motility of freshly diluted semen was assessed after covering a semen drop on a glass slide with a thin cover slip at $37^{\circ} \mathrm{C}$, under high 
power magnification $(40 \times)$. The individual motility was recorded as the percentage of progressive motile sperm. Sperm livability percentage was calculated by using EosinNigrosin stain. Similarly, the abnormal sperm percentage was calculated by using Rose Bengal stain under high power magnification $(100 \times)$ [17]. Percent intact acrosome was assessed by staining the semen smears with Giemsa stain [18]. The bovine cervical mucus penetration test (BCMPT) was carried out by following the procedure described earlier [19], in which distance $(\mathrm{mm})$ traveled by progressive sperm was measured under high power microscopic magnification $(40 \times)$, by allowing sperm to travel in a capillary tube, filled with cervical mucus of a cyclic cow, at $37{ }^{\circ} \mathrm{C}$ for $60 \mathrm{~min}$. The percentage of a hypo-osmotic swollen sperm was observed by incubating semen with a hypo-osmotic solution at $37{ }^{\circ} \mathrm{C}$ for $60 \mathrm{~min}$ and examining the swelling of the sperm tail under high power microscopic magnification $(40 \times)$ for the hypo-osmotic sperm swelling test [20].

Alkaline phosphatase [21], acid phosphatase [22], glutamic oxaloacetic transaminase [GOT] and glutamic pyruvic transminase [GPT] activity [23] in seminal plasma was estimated using diagnostic kits (Glaxo), manufactured by Sigma Diagnostic Pvt. Ltd., Baroda, India.

\subsection{Collection of blood and estimation of serum testosterone level}

Blood samples were collected from all four groups of bulls at monthly intervals and serum was separated by centrifugation of samples at $3000 \mathrm{rpm}$ for $20 \mathrm{~min}$. The separated serum was stored at $-20{ }^{\circ} \mathrm{C}$ in sterilized glass vials for estimation of testosterone. Testosterone concentration in blood serum samples was determined using RIA kits supplied by Immunotech, France. The unknown samples and standard samples were incubated with ${ }^{125} \mathrm{I}$ serum-labeled testosterone in antibodycoated tubes. After incubation, the liquid content of the tubes was aspirated and the bound radioactivity was determined in a gamma counter (Packard, USA). A standard curve was prepared with 6 standards and testosterone concentration in unknown samples was obtained from the curve by interpolation.

\subsection{Statistical analysis}

The data collected during the period of study were analyzed as per method described by Snedecor and Cochran [24], using one-way analysis of variance and significant means were compared using the Duncan multiple range test [25].

\section{RESULTS}

\subsection{Semen characteristics of bulls at the start of the experiment}

The mean values of quantitative (ejaculate volume $(\mathrm{mL})$, concentration of sperm (million. $\mathrm{mL}^{-1}$ ) and number of sperm per ejaculate (million)) and qualitative characteristics (semen $\mathrm{pH}$, mass motility $(0-5$ points scale), individual motility (\%), sperm livability (\%), abnormal sperm $(\%$, intact acrosome $(\%)$, BCMPT (mm), HOSST (\%), GOT (unit.mL $\mathrm{mL}^{-1}$ ), GPT (unit. $\mathrm{mL}^{-1}$ ), alkaline phosphatase (KAU.100 $\mathrm{mL}^{-1}$ ) and acid phosphatase (KAU.100 $\mathrm{mL}^{-1}$ )) of semen of 16 crossbred cattle bulls at the start of experiment are presented in Table I and the results revealed no significant difference in any of these parameters.

\subsection{Semen characteristics of bulls after 6 months of zinc supplementation}

The mean values of semen quantitative and qualitative characteristics and 
Table I. Semen quantitative and qualitative characteristics of crossbred bulls at the start of the experiment.

\begin{tabular}{lc}
\hline Quantitative Characteristics & Mean $( \pm \mathrm{SE})$ \\
\hline Semen volume $(\mathrm{mL})$ & $2.84 \pm 0.13$ \\
Sperm concentration (million. $\left.\mathrm{mL}^{-1}\right)$ & $785 \pm 62.1$ \\
Sperm number per ejaculate (millions) & $2229 \pm 226.9$ \\
\hline Qualitative characteristics & Mean $( \pm \mathrm{SE})$ \\
\hline Semen pH & $6.64 \pm 0.04$ \\
Mass motility (0-5 scale) & $3.15 \pm 0.96$ \\
Individual motility (\%) & $75.11 \pm 1.35$ \\
Sperm Livability (\%) & $77.05 \pm 1.24$ \\
Abnormal sperm (\%) & $12.0 \pm 1.10$ \\
Intact acrosome (\%) & $78.69 \pm 1.35$ \\
BCMPT (mm)* & $15.94 \pm 2.05$ \\
HOSST (\%)** & $48.44 \pm 2.53$ \\
Alkaline phosphatase (KAU***.100 $\left.\mathrm{mL}^{-1}\right)$ & $135.21 \pm 12.73$ \\
Acid phosphatase (KAU.100 $\left.\mathrm{mL}^{-1}\right)$ & $254.89 \pm 26.87$ \\
Glutamic oxaloacetic transaminase $\left(\mathrm{unit}^{*} \mathrm{~mL}^{-1}\right)$ & $492.38 \pm 2.82$ \\
Glutamic pyruvic transaminase (unit. $\left.\mathrm{mL}^{-1}\right)$ & $35.24 \pm 0.72$ \\
\hline
\end{tabular}

* mm: Mean penetration distance traveled by bull sperm in cyclic bovine cervical mucus.

** \% of sperm reactive to hypo-osmotic sperm swelling test.

*** KAU: King and Armstrong Unit. It is defined as the quantity of phosphatase that acting upon disodium phenyl phosphate in excess at $\mathrm{pH} 9$ for 30 min liberates $1 \mathrm{mg}$ of phenol. It is the standard of measure devised by King and Armstrong. For Alkaline and acid phosphatase $1 \mathrm{KAU} \cdot \mathrm{dl}^{-1}=1 \mathrm{IU} / \mathrm{L} / 7$. Therefore, $7 \mathrm{KAU} \cdot \mathrm{dl}^{-1}=1 \mathrm{IU} \cdot \mathrm{L}^{-1}$.

blood serum testosterone concentration (ng. $\mathrm{mL}^{-1}$ ) in crossbred cattle bulls of different groups after 6 months of Zn supplementation are presented in Table II.

\subsubsection{Quantitative characteristics of semen}

The results revealed that mean ejaculate volume $(\mathrm{mL})$, sperm concentration (million. $\mathrm{mL}^{-1}$ ) and sperm number per ejaculate (millions) in different groups of crossbred cattle bulls were affected positively due to $\mathrm{Zn}$ supplementation. Mean ejaculate volume (mL) was significantly $(P<0.05)$ lower in-group I (control) as compared to all $\mathrm{Zn}$-supplemented groups (groups II, III and IV) and increased significantly with an increase in level of $\mathrm{Zn}$ in the diet; however, there was no significant difference in-group III (70 ppm Zn as $\mathrm{Zn}$ sulphate) and group IV (35 ppm $\mathrm{Zn}$ as $\mathrm{Zn}$ propionate). Sperm concentration (million. $\mathrm{mL}^{-1}$ ) and sperm number per ejaculate (million) were significantly $(P<0.01)$ higher in the $\mathrm{Zn}$-supplemented groups as compared to the control. Though the sperm concentration (per $\mathrm{mL}$ ) was statistically alike in groups III and IV, the sperm number per ejaculate was significantly $(P<0.01)$ higher in group IV as compared to the 3 other groups, which indicated a better effect of organic $\mathrm{Zn}$ ( $\mathrm{Zn}$ propionate) as compared to inorganic $\mathrm{Zn}$ (Zn sulphate) on sperm production. 


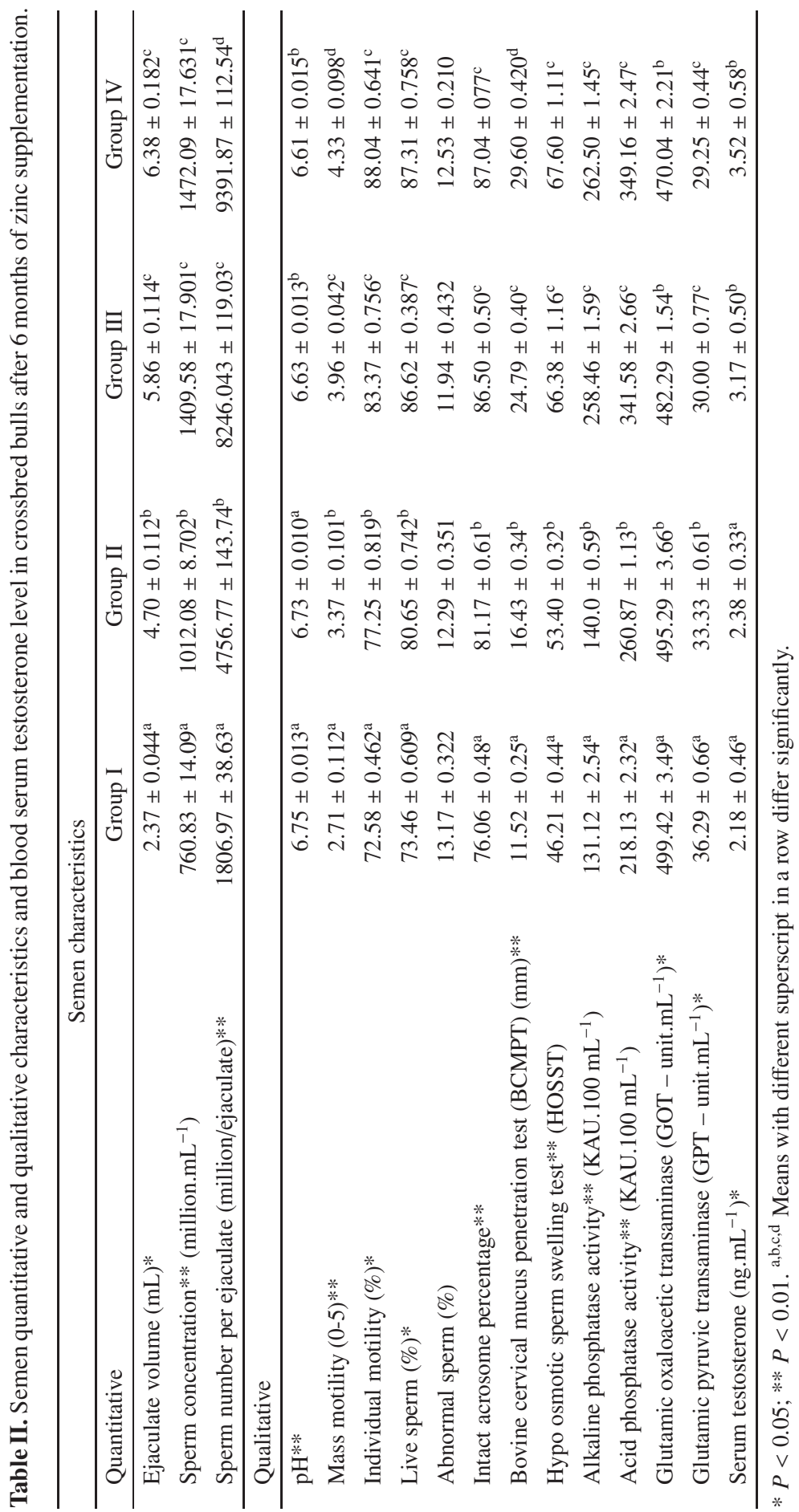




\subsubsection{Qualitative characteristics of semen}

The result revealed significantly $(P<$ $0.01)$ lower semen $\mathrm{pH}$ in-group III and group IV as compared to groups II and I, but values were with in normal range. The mean mass motility values $(0-5$ scale) were significantly $(P<0.01)$ different between all four groups. Mean individual sperm motility (\%) in different groups of crossbred bulls differed significantly $(P<$ $0.01)$, indicating significantly $(P<0.01)$ higher sperm motility in Zn-supplemented groups. The highest mean livability (\%) was recorded in-group IV, which was significantly $(P<0.01)$ higher than groups II and $\mathrm{I}$ and non-significantly $(P>0.05)$ higher than group III. The results revealed no significant difference in mean abnormal sperm (\%) in four groups of cattle bulls. The results revealed a progressive increase in intact acrosome (\%), indicating a significantly $(P<0.01)$ higher intact acrosome percentage in $\mathrm{Zn}$-supplemented groups as compared to the control group. The BCMPT indicated that mean penetration distance $(\mathrm{mm})$ traveled by the crossbred bull sperm in the bovine estrus mucus was maximum in group IV (29.60) followed by group III (24.79), group II (16.43) and group I (11.52). The difference in penetration distance among all groups was significantly $(P<0.01)$ different. The HOSST indicated higher mean percentage of hypo osmotic swollen sperms in-group IV (67.60), followed by group III (66.38), group II (53.40) and group I (46.21). The values of HOSST in $\mathrm{Zn}$ supplemented groups differed significantly $(P<0.01)$ from the control group, but values between group III and group IV were statistically alike. The mean activities of alkaline phosphatase and acid phosphatase (KAU.100 $\mathrm{mL}^{-1}$ ) in seminal plasma were significantly $(P<0.01)$ higher in $\mathrm{Zn}$ supplemented groups as compared to the control group. The results further revealed that there was a progressive significant $(P<0.01)$ decrease in GOT and GPT activity (unit. $\mathrm{mL}^{-1}$ ) in crossbred bulls from group I to group IV, indicating a significant difference in the $\mathrm{Zn}$-supplemented and control group. Mean serum testosterone concentration (ng. $\mathrm{mL}^{-1}$ ) were found to be $2.18,2.38,3.17$ and 3.52 in 4 groups of crossbred cattle bulls, respectively. No significant difference was observed in groups I and II but significantly $(P<0.05)$ higher values were found in-group III and group IV as compared to the control group.

\section{DISCUSSION}

In this study, the effect of different levels and sources of zinc supplementation on semen quantitative and qualitative characteristics and blood serum testosterone level of crossbred cattle bulls was studied. The results revealed that supplementation of $\mathrm{Zn}$ in the inorganic form (Zn sulphate) and organic form (Zn propionate) improved the semen quality of bulls as compared to the non-supplemented control group. $\mathrm{Zn}$ propionate was better than $\mathrm{Zn}$ sulfate in almost every character of semen studied. This might be due to the fact that $\mathrm{Zn}$ propionate has got more bioavailability than $\mathrm{Zn}$ sulfate, as a result, there might have been more absorption, distribution and uptake of $\mathrm{Zn}$ in the $\mathrm{Zn}$ propionate supplemented group, which accounts for its better effect over $\mathrm{Zn}$ sulfate. Our study is perhaps the first study correlating $\mathrm{Zn}$ propionate and semen quality of crossbred cattle bulls.

\subsection{Semen quantitative and qualitative characteristics of crossbred cattle bulls at the start of the experiment}

At the start of the experiment, semen was collected from all 16 bulls and evaluated for quantitative and qualitative characteristics. The results revealed that all the 
bulls were having normal semen quality. The mean values of quantitative and qualitative seminal parameters did not differ significantly among bulls at the start of the experiment.

\subsection{Semen quantitative characteristics of crossbred cattle bulls after 6 months of $\mathrm{Zn}$ supplementation}

The results revealed significantly $(P<$ 0.05 ) higher values of ejaculate volume in groups supplemented with $\mathrm{Zn}$ sulfate and $\mathrm{Zn}$ propionate as compared to the control group of bulls. The present results are in agreement with the findings of earlier researchers who observed increased semen volume when they supplemented $\mathrm{Zn}$ sulfate in the diet of goats [26] and rabbits $[27,28]$. However, no published report was available in the literature on the effect of $\mathrm{Zn}$ propionate supplementation on semen quality in ruminants; probably this is the first report showing the effect of zinc propionate supplementation on semen of crossbred cattle bulls. Semen volume mainly constitutes secretion of the testes, epididymis and accessory sex glands, especially prostate gland. Zn has been reported to stimulate growth and development of primary, secondary and accessory sex organs as evidenced by atrophy of these organs in rams, when they were fed a $\mathrm{Zn}$ deficient diet [7]. The main source of zinc in the semen is the prostate gland where the highest concentration of $\mathrm{Zn}$ has been demonstrated, and it acts as a marker of prostatic functions $[29,30]$. So, enhanced semen volume by $\mathrm{Zn}$ supplementation may be attributed to increased secretory activity of prostatic cells, since $35-40 \%$ semen volume is contributed by the prostate gland. In the present study, we recorded a highly significant $(P<0.01)$ increase in sperm concentration and sperm number per ejaculate in all the $\mathrm{Zn}$-supplemented groups as compared to the control group, which indicated a beneficial effect of $\mathrm{Zn}$ on spermatogenesis. Similar results were observed in men [3], rams [5], bucks [26] and rabbits [27], when $\mathrm{Zn}$ was supplemented in their diet. This may be due to the fact that $\mathrm{Zn}$ plays an indispensable role in spermatogenesis. The production of sperm necessitates extensive cell division and $\mathrm{Zn}$ plays a significant role in it by influencing mitotic and meiotic cell divisions, along with synthesis of DNA and RNA by enhancing the activity of DNA polymerase and RNA polymerase, the two Zn containing enzymes. Zn also helps in encoding a transcription factor involved in spermatogenesis [31]. $\mathrm{Zn}$ is also involved in the activation and maintenance of the germinal epithelium of semineferous tubules and also stimulates production and secretion of testosterone, which influences spermatogenesis [3]. Moreover, most important enzymes involved in the process of spermatogenesis are sorbitol dehydrogenase and lactate dehydrogenase, which are essentially zinc metalloenzymes [32]. All these factors may account for improved sperm concentration and sperm number per ejaculate in $\mathrm{Zn}$-supplemented groups.

\subsection{Semen qualitative characteristics of crossbred cattle bulls after 6 months of zinc supplementation}

The results revealed significantly $(P<$ 0.01 ) lower semen $\mathrm{pH}$ in groups III and IV, as compared to groups I and II, but values were with in the normal $\mathrm{pH}$ range. These results are contradictory with those of [26], who reported an increased $\mathrm{pH}$ value in $\mathrm{Zn}$ supplemented bucks. The difference in $\mathrm{pH}$ values may be due to the species difference and also the short duration of zinc supplementation in their study as compared to long term $\mathrm{Zn}$ supplementation in the present study. In our study, reduced semen $\mathrm{pH}$ might be attributed to increased acidic secretion of the prostate gland in semen 39. 
Supplementation of $\mathrm{Zn}$ in the diet of cattle bulls revealed significant improvement in both mass and individual motility in all $\mathrm{Zn}$ supplemented groups as compared to the control group. Our results were in agreement with previous reports in men [3], sheep [5] and rabbits [27]. Improved sperm motility may be due to the fact that the primary donor of energy needed by the sperm flagella for movement is ATP and Zn controls the motility of sperm by controlling energy utilization through the ATP system, through regulation of phospholipid energy reserves and improving sperm oxygen uptake [33]. Another reason for the enhancement of sperm motility in $\mathrm{Zn}$ supplemented groups may be the increased activity of $\mathrm{Zn}$ containing enzymes viz. sorbitol dehydrogenase and lactate dehydrogenase which play significant roles in sperm motility [30]. $\mathrm{Zn}$ is also a scavenger of free oxygen radical and protects sperm from oxidative damage and lipid per oxidation by inhibiting phospholipase [32] Thus, the anti-oxidant action of Zn may be responsible for improved motility of sperm in Zn-supplemented groups. In the present study, it was observed that supplementation of $\mathrm{Zn}$ above the recommended level in the diet of crossbred cattle bulls resulted in a highly significant $(P<0.01)$ increase in live sperm percentage. Our results were in accordance with the findings of earlier researchers in the rabbit [33] and man [34], who reported improved live sperm percentage by $\mathrm{Zn}$ supplementation. Improved livability of sperm may be due to the membrane stabilizing action of $\mathrm{Zn}$, by virtue of which, it prevents leakage of enzymes, proteins and other vital components of sperm, thus extending the functional life of sperm. Moreover, $\mathrm{Zn}$ also stabilizes ribosomes, lysosomes, DNA and RNA, which help in survival and normal functioning of the sperm [35]. They further reported that $\mathrm{Zn}$ protects sperm from free radical induced damages by scavenging excessive free radicals and thus improving sperm viability. Bires et al. [36] reported that $\mathrm{Zn}$, as a constituent of a large number of metalloenzymes, is involved in several enzymatic reactions associated with carbohydrate, protein, lipid and nucleic acid metabolism, which may account for improved sperm livability. Moreover, $\mathrm{Zn}$ has been reported as a primary factor responsible for the production of an anti-bacterial substance released from the prostate gland into semen [39], which may also account for improved live sperm percentage. Abnormal sperm (\%) present in the semen of different groups of bulls varied from $11-13 \%$, indicating that $\mathrm{Zn}$ supplementation did not affect this character. The present findings were in agreement with those of $[37,38]$, who also did not observe any change in abnormal sperm percentage, when they supplemented $\mathrm{Zn}$ in the diet of men and boars, respectively. The normal and abnormal morphology of sperm is completely dependent on the spermiogenesis phase of spermatogenesis, which in turn is regulated by Sertoli cells [39] and $\mathrm{Zn}$ deficiency did not have any structural and functional changes on sertoli cells [40]. Since there was no effect of zinc on Sertoli cells, so, no significant difference was observed in abnormal sperm percentage in different groups of crossbred cattle bulls.

Intact acrosome percentage was significantly $(P<0.01)$ higher in $\mathrm{Zn}$ supplemented groups as compared to the control group. Improved intact acrosome (\%) in $\mathrm{Zn}$-supplemented groups may be attributed to anti-oxidant properties and membrane stabilizing action of $\mathrm{Zn}$ modulates the stability of the acrosomal membrane by inhibiting lipid per oxidation by influencing phospholipase, resulting in a fluidity change [32]. $\mathrm{Zn}$ has been found to stabilize various acrosomal enzymes like acrosin, acid phosphatase and phospholipase, which may account for improved intact acrosome percentage. Moreover, acrosome is a highly specialized form of lysosomes and $\mathrm{Zn}$ has been reported 
to stabilize and inhibit libilization of lysosomes [41].

In the present study, the maximum cervical mucus sperm penetration distance $(\mathrm{mm})$ value was observed by sperm of the $35 \mathrm{ppm} \mathrm{Zn}$ propionate supplemented group of bulls followed by $70 \mathrm{ppm}$ and $35 \mathrm{ppm} \mathrm{Zn}$ sulfate supplemented groups and the lowest penetration distance was observed in the control group of bulls. Since no report is available in the literature on the effect of supplemental zinc on BCMPT, the present results could not be compared. Improved values of BCMPT in $\mathrm{Zn}$-supplemented groups may be due to improved motility and livability percentage of sperm in the Zn-supplemented groups, since sperm the penetration depends on the number of motile and viable sperm [42]. Higher intact acrosome percentage in $\mathrm{Zn}$ supplemented groups might also account for it, since it helps in the penetration of sperm in the cervical mucus [43]. One of the most important factors influencing the sperm penetration through the cervical mucus is the presence of anti-sperm antibodies in seminal plasma, which reduces normal progression of sperm through cervical mucus. Kramer and Jager [44] demonstrated that $\mathrm{Zn}$ - reduces the level of antisperm antibody in the semen, which may be implicated in the improved penetration values in $\mathrm{Zn}$-supplemented groups in the present study.

The result of HOSST revealed that the sperm of $\mathrm{Zn}$-supplemented groups of bulls had higher tail swelling, after hypo-osmotic treatment, as compared to the control group of bulls. The results were in agreement with those of previous researchers who observed significant increase in HOSST response by supplementing $\mathrm{Zn}$ in the diet of men [34] and sheep [5]. HOSST measures single factor i.e. membrane integrity and $\mathrm{Zn}$ has been reported to elicit membrane stabilizing action by interacting with some functional group of the intrinsic component of sperm membrane. It refers to the formation of stable mercapeptides by reacting with the -SH group of membrane protein, which changes fluidity and stabilizes the membrane [32]. Improved HOSST response may be attributed to increased motility and livability of sperm in $\mathrm{Zn}$ supplemented groups. It is a known fact that sperm motility and livability is dependent upon membrane transport and it finds support from the results of the present study, where higher motility, livability and HOSST responses were recorded in all $\mathrm{Zn}$ supplemented groups.

In the present study, a highly significant $(P<0.01)$ increase in alkaline phosphatase activity was observed in $\mathrm{Zn}$ supplemented groups as compared to the control. Though, no report is available in the literature for the comparison of the results of the present study, our findings are indirectly supported by reports in which alkaline phosphatase activity in serum was greatly reduced in zinc deficient animals [45]. The increased alkaline phosphatase activity by $\mathrm{Zn}$ supplementation may be due to the fact that, it is a $\mathrm{Zn}$ dependent metalloenzyme and requires $\mathrm{Zn}$ ions not only as an integral part of their catalytic apparatus but also as a structure stabilizing factor [39].

Significantly $(P<0.01)$ higher values of acid phosphatase activity in seminal plasma were observed in $\mathrm{Zn}$-supplemented groups as compared to the control. Our results are in agreement with those of earlier workers [46] who observed increased acid phosphatase activity in men supplemented with $\mathrm{Zn}$ in their diet. Acid phosphatase is a specific secretary product of the prostate gland. The main source of $\mathrm{Zn}$ in semen is the prostate gland and it is required for normal functioning of the prostate, so an improved value of acid phosphatase in seminal plasma might be due to the stimulatory action of $\mathrm{Zn}$ on the prostate gland.

The mean GOT and GPT activity in seminal plasma of different groups of 
crossbred bulls revealed significantly $(P<$ $0.05)$ lower values in $\mathrm{Zn}$-supplemented groups as compared to the control group. It is mainly attributed to anti-oxidant and membrane stabilizing action of $\mathrm{Zn}$, which causes lesser release of these enzymes in seminal plasma.

The mean blood serum testosterone concentration (ng. $\mathrm{mL}^{-1}$ ) in Zn-supplemented groups was significantly $(P<0.05)$ higher than the control group of bulls. The results of the present study are in close agreement in man [47] and the rabbit [33]. However, no significant difference in testosterone levels was observed by $\mathrm{Zn}$ supplementation in the rabbit [25], man [34] and crossbred bulls [48], which may be due to species variation, different duration and level of zinc supplementation. Improved values of testosterone in $\mathrm{Zn}$-supplemented groups might be due to stimulatory effect of zinc on testicular steroidogenesis [49], since $\mathrm{Zn}$ affects testicular functions by activating the adenyl cyclase system, which stimulates testosterone synthesis [33]. It was reported that $\mathrm{Zn}$ stimulates Leydig cells of the testis and enhances the production of testosterone [49] since $\mathrm{Zn}$ is an essential component of protein involved in synthesis and secretion of testosterone.

\section{CONCLUSION}

It may be concluded that supplementation of $\mathrm{Zn}$ in the diet of crossbred cattle bulls improved semen quality in terms of quantitative and qualitative characteristics of semen, as compared to the non-supplemented control group, however, the organic form of $\mathrm{Zn}$ ( $\mathrm{Zn}$ propionate) showed a better response in improving sperm per ejaculate, mass motility and semen fertility test like bovine cervical mucus penetration, as compared to the inorganic form of $\mathrm{Zn}$ ( $\mathrm{Zn}$ sulfate) at the same and higher level of supplementation.

\section{ACKNOWLEDGEMENTS}

The authors are grateful to the Director of the Indian Veterinary Research Institute, Izatnagar for providing the necessary facilities for carrying out this research work. The first author is thankful to the Indian Council of Agricultural Research, Krishi Bhawan, New Delhi for providing financial assistance in the form of a junior research fellowship. We are thankful to $\mathrm{M} / \mathrm{s}$ Kemin, Chennai for providing a free sample of zinc propionate for carrying out this study. This work was carried out under AP Cess Scheme of the Indian Council of Agricultural Research, Krishi Bhawan, New Delhi.

\section{REFERENCES}

[1] Smith OB, Akinbamizo OO. Micronutrients and reproduction in farm animals. Anim Reprod Sci 2000, 60-61: 549-560.

[2] Ebisch TMW, Van Heerde WL, Thomos CMG, Vander Put N, Wong WY. Steegers Theunissen RPM C677T methylene tetrahydrofolate reductase polymorphism interfere with effect of folic acid and zinc sulphate on sperm concentration. Fertil Steril 2003, 80: 1190-1194.

[3] Wong WY, Merkus HM, Thomas CM, Menkveld R, Zielthuis GA, SteegersTheunissen RP. Effect of folic acid and zinc sulphate on male factor sub fertility, a double blind, randomized placed controlled trial. Fertil Steril 2002, 77: 491-498.

[4] Wroblewski N, Schill WB, Henkel R. Metal chelators change the human sperms motility pattern. Fertil Steril 2003, 79 (Suppl 3): 1584-1589.

[5] Kendall NR, McMullan S, Green A, Rodway RG. Effect of zinc, cobalt and selenium soluble glass bolus on trace element status and semen quality of ram lambs. Anim Reprod Sci 2000, 62: 277-283.

[6] Suruki T, Nakajima K, Yamamoto A, Yamanaka H. Metallothionein binding zinc inhibits nuclear chromatin decondensation of human spermatozoa. Andrologia 1995, 27: 161-164.

[7] Martin GB, White CL, Markey CM, Blackberry MA. Effect of dietary zinc deficiency on the reproductive system of young male sheep: testicular growth and the secretion of inhibin and testosterone. J Reprod Fertil 1994, 101: 87-96. 
[8] Chia SE, Ong CN, Chua LH, Ho LM, Tay SK. Comparison of zinc concentration in blood and seminal plasma and the various sperm parameters between fertile and infertile men. J Androl 2000, 21: 53-57.

[9] Massonyi P, Tomon R, Trandzik J, Nad P, Skalicka M, Korenekova. Concentration of copper, zinc, iron, cadmium, lead and nickel in bull, ram, boar, stallion and fox semen. Trace Element Electrolyte 2004, 21: 45-49.

[10] NRC. Nutrient Requirement of Dairy Cattle. National Academy Press, Washington, DC, 1989.

[11] Engle TE, Nocks CF, Kimberling CV, Weabe DL, Johnson AB. The effect of feeding organic and inorganic zinc on biochemical parameters in zinc deficient calves. Proc West Sect Am Soc Anim Sci 1995, 46: 471-474.

[12] Spears JW, Harvey RW, Brown TT Jr. Effect of zinc methionine and zinc oxide on performance, blood characteristics and antibody titer response to viral vaccination in stressed feeder calves. J Am Vet Med Assoc 1991, 199: 1731-1733.

[13] Droke EA, Gengelbach GP, Spears JW. Influence of level and source (inorganic vs. organic) of zinc supplementation on immune function in growing lambs. Asian Aust J Anim Sci 1998, 11: 139-144.

[14] Sonada S, Yashida O. Zinc concentration and total amount of zinc in seminal plasma of infertile man with special reference to prostatic secretary function. Hinyokikakiyo 1985, 31: 1971-1987.

[15] Mohan H, Verma J, Singh I, Mohan P, Marwah S, Singh, P. Interrelationship of zinc levels in serum and semen in oligospermic infertile patients and fertile males. Indian $\mathrm{J}$ Pathol Microbiol 1997, 40: 451-455.

[16] Salisbury GW, Van Denmark NL, Lodge JR. Physiology of Reproduction and Artificial Insemination of Cattle, 2nd ed, CBS Publishers and Distributors, Sahadra, Delhi, India, 1985, pp 407-415.

[17] Tomar NS. Artificial Insemination and Reproduction of Cattle and Buffaloes, Saroj Publishers, Allahabad, India, 1997, pp 95-99.

[18] Watson PF. Use of Giema stain to detect changes in acrosome of frozen ram spermatozoa. Vet Rec 1975, 97: 12-15.

[19] Matousek J, Riha J, Srean V, Veselsky L, Launda F. Penetration of cervical mucus and other body fluids by bull sperm in capillary tube. Anim Reprod Sci 1989, 18: 161-166.
[20] Jeyendran RS, Vanderven HH, Perezpelaez M, Crabo BG, Zaneveld LJD. Development of an assay to assess the functional integrity of the human sperm membrane and its relationship to other semen characteristics. J Reprod Fertil 1984, 70: 219-228.

[21] Kind PRM, King EJ. Estimation of serum alkaline phosphatase activity by colorimetric method. J Clin Pathol 1954, 7: 322.

[22] Kind EJ, Armstrong AR. Practical Clinical Biochemistry, 3rd ed, Inter Science Books, Inc, New York, 1954.

[23] Reitman S, Frankel SE. A colorimetric method for the determination of serum glutamic oxaloacetic transaminase and serum glutamic pyruvic transaminase. Am J Clin Pathol 1957, 28: 56.

[24] Snedecor GW, Cochran WG. Statistical method, 6th ed. The Iowa State University Press, Ames, Iowa, USA, 1989.

[25] Steel RGD, Torrie GH. Principles and procedures of statistics: A biometrical approach, 2nd ed. McGraw Hill, New York, 1980, p 633.

[26] Saleh AM, Ibrahim, Yousri RM. The effect of dietary zinc, season and breed on semen quality and body weight in goat. Int. J Anim Sci 1992, 7: 5-12.

[27] Tharwat EE. The use of $\mathrm{ZnSO}_{4}$ to improve semen characteristics and fertility of New Zealand White rabbit buck during hot season. Ann Agric Sc, Cairo 1998 (Special issue) 3: 750-770

[28] Moce E, Arouca M, Lavara R, Auscal P. Effect of dietary zinc and vitamin supplementation on semen characteristics of high growth rate males during summer season. In: Proceeding Valencia, World Rabbit Congress, 2000.

[29] Elzanaty S, Malm J, Jiwercman A. Viscoelasticity of seminal fluid in relation to the epidymal and accessory sex gland function and its impact on sperm motility. Int J Androl 2004, 27: 94-100.

[30] Nagamine CM, Chan K Hake LE, Lau YFC. The two-candidate testis determining Y genes (Zfy-1 and Zfy-2) are differentially expressed in fetal and adult mouse tissues. Genes Dev 1990, 4: 63-74.

[31] Bedwal RS, Bahuguna A. Zinc, copper and selenium in reproduction. Experentia 1994, 50: 625-640.

[32] Eggert Kruss W, Zwick EM, Batschulat K, Rohr G, Armbruster FP, Petzoldt D, Strowitzki T. Are zinc level in seminal 
plasma associated with seminal leukocyte and other determinant of semen quality. Fertil Steril 2002, 17: 260-269.

[33] El-Masry K, Anasr AS, Kamal TH. Influences of season and dietary supplementation with selenium and vitamin $\mathrm{E}$ or zinc on some blood constituents and semen quality of New Zealand White rabbit males. World Rabbit Sci 1994, 2: 79-86.

[34] Omu AE, Dashti H, Al-Othman S. Treatment of asthenozoospermia with zinc sulphate: andrological, immunological and obstetric outcome. Eur J Obst Gynaecol Reprod Biol 1998, 79: 179-184.

[35] Bettger W, O'Dell BA. Critical physiological role of zinc in the structure and function of biomembranes. Life Sci 1981, 28: 14251438.

[36] Bires J, Bartko P, Huska M. Distribution of risk element in the organism of sheep after industrial intoxication with zinc. Spectroscopic Lett 1997, 30: 1263-1277.

[37] Kyanaston HG, Lewis DI, Lynch RV, Deshmond AD. Changes in seminal quality following oral zinc therapy. Andrologia 1988, 20: 21-22.

[38] Liao CW, Chyr SC, Shen TF. The effect of dietary zinc content on reproductive performance of the boar. In: Proc Third EAAP, Animal Science Congress, Seoul, Korea Republic, 1985, 2: 613-615.

[39] McDonald LE. Veterinary Endocrinology and Reproduction, 5th ed. Lea and Febiger, Iowa State Press, Ames, Iowa, 2003.

[40] Veda H, Koyama F, Mori N, Doi Y, Fujmoto S. Effect of dietary zinc deficiency on protein secretary function of the mouse testis. Arch Histol Cytol 1991, 54: 401-410.
[41] Gavella M, Lipovac V. In vitro effect of zinc on oxidative changes in human semen. Andrologia 1998, 36: 317-323.

[42] Dev S, Pangawkar GR, Sharma RK Matharoo JS. Sperm mucus penetration and its relation to semen quality of buffalo bulls. Indian J Anim Sci 1996, 66: 713-715.

[43] Kumar N. Effect of zinc supplementation on seminal attributes and serum testosterone level with special reference to in vitro fertility tests in crossbred bulls. MV Sc Thesis submitted to Deemed University, IVRI, Izatnagar, India, 2003.

[44] Kremer J, Jager S. Characterization of antisperm antibodies responsible for shaking phenomenon with special regard to immunoglobulin class and antigen reactive sites. Int J Androl 1980, 3: 143.

[45] Eltohomy MM, Younis M. Response of testes, epididymis and seminal vesicle of rabbit to zinc deficiency. Arch Exp Veterinarmed 1991, 45: 155-160.

[46] Tikkiwal M, Ajmera RL, Mathur NK. Effect of zinc administration on seminal zinc and fertility of oligospermic males. Indian J Physiol Pharmacol 1987, 31: 30-35.

[47] Hartoma TR, Nahoul K, Netter A. Zinc, androgen and male sterility. Lancet 1977, 2: 1125-1126.

[48] Mandal GP. Effect of zinc supplementation on growth, metabolic profile and immunity in crossbred calves. PhD thesis IVRI, Deemed University, Izatnagar, India, 2004, p 98.

[49] Fang VS, Furushasi N. Partial alleviation of the antitesticular effect of pipecolinomethylhydroxy indane by zinc in rats. J Endocrinol 1978, 79: 151 . 